\title{
Using the Socio-Ecological Model to Frame the Influence of Stakeholders on Cocoa Farmers' Pesticide Safety in Nigeria: Findings from a Qualitative Study
}

\author{
Oluseye O Oludoye (iD) ${ }^{1,2}$ \\ Mark G Robson ${ }^{3,4}$ \\ Wattasit Siriwong (iD ${ }^{5}$
}

'International Postgraduate Program in Hazardous Substance and Environmental Management, Graduate School, Chulalongkorn University, Bangkok, 10330, Thailand; ${ }^{2}$ Center of Excellence on Hazardous Substance Management (HSM), Chulalongkorn University, Bangkok, 10330, Thailand; ${ }^{3}$ Office of Continuing Professional Education, New Jersey Agricultural Experiment Station, Rutgers University, New Brunswick, NJ, USA; ${ }^{4}$ Department of Plant Biology, School of Environmental and Biological Sciences, Rutgers University, New Brunswick, NJ, USA; ${ }^{5}$ College of Public Health Sciences, Chulalongkorn University, Bangkok, 10330, Thailand
Correspondence: Wattasit Siriwong Email wattasit.s@chula.ac.th
Purpose: The aim of this study was to explore the roles of stakeholders on cocoa farmers' safe pesticide use in Nigeria using the socio-ecological model as the theoretical framework. Methods: This was a cross-sectional qualitative study where participants were purposefully selected based on some criteria. Then, they were interviewed in-depth using a semistructured interview approach. The interview guide was designed based on other literature and the study objectives. The interview transcripts were transcribed verbatim and analyzed using the content analysis technique.

Results: In all, 57 participants were involved in the interview process across all the study locations. Five layers of influence (cocoa farmers, pesticide retailers, extension officers, pesticide importers and government agencies) were considered. At individual level, cocoa farmers complained about lack of information from other stakeholders regarding pesticide use except retailers due to the farmers' proximity to their stores. However, pesticide safety information from the retailers were found to be inadequate due to their interest in financial gains rather than a focus on human health and the environment. Additionally, most retailers had no understanding about the characteristics of products they sold as they could not read pesticide labels. Furthermore, lack of motivations, human resources and facilities hindered effective extension education in the rural communities. Also, pesticide importers took efforts to train the farmers within their network, but majority of these trainings focused on lead farmers who were expected to disseminate the information to others. Besides, the agencies did organize training or workshop sometimes, but it was inadequate due to budget constraint. Lastly, environmental or agri-policies relating to Nigerian cocoa farmers concerning safe pesticide use and disposal were also inadequate.

Conclusion: Generally, there was a large information gap with respect to pesticide safety between cocoa farmers and other stakeholders which undermined pesticide use safety. This study highlighted the need for government agencies in Nigeria to develop mechanisms to monitor information exchange among other stakeholders and cocoa farmers with respect to safe pesticide use and disposal.

Keywords: pesticide retailers, extension officers, pesticide importers, agri-policies, in-depth interview

\section{Introduction}

Agriculture, being the second largest source of labour, is one of the most dangerous occupations in the world. ${ }^{1}$ This is because many agricultural workers such as farmers are exposed to accidents from pesticide exposure. ${ }^{2}$ Due to their efficacy 
for crop protection against pests and diseases, pesticides are universally adopted among farmers as the main agroinput in farming. ${ }^{3}$ About three million farmers suffer yearly from hazardous impact of pesticide poisoning; this includes 25 million farmers that suffer from mild poisoning, causing about 180,000 mortalities annually.,5 Pesticide exposure occurs via ingestions, breathing and dermal contact among farmers and could result in adverse health problems. ${ }^{6}$ For example, European residents and bystanders were reported to have been exposed to pesticides through breathing or dermal contacts while spraying on fields specifically in countries like Italy, Greece and United Kingdom. ${ }^{7}$ In addition, unsafe pesticide use accompany with adverse health impact have also been reported in the developing agricultural nations such as Morocco, Indonesia, Iran and Thailand. ${ }^{8-11}$ For instance, pesticides related symptoms such as headache, fatigue and itching were reported among $29.4 \%, 45.9 \%$ and $57.6 \%$ of study participants in Thailand, respectively. ${ }^{9}$ Moreover, workrelated pesticide symptoms have also been reported among roughly $23 \%$ Indian, 25\% Mexican and $43 \%$ Zimbabwean farmers. ${ }^{12}$ However, this reported undesirable impacts of pesticides on farmers health and the environment could be reduced through a more eco-friendly pest management practices. ${ }^{13}$ In fact, these have been achieved in some developing countries especially in Indonesia via successful implementation of integrated pest management (IPM) as a crop protection strategy. ${ }^{14}$

In Nigeria, agriculture alone contributed $21.96 \%$ of the gross domestic product (GDP), with crop production accounting for $90.54 \% .{ }^{15}$ In order to boost productivity, cocoa farmers are using pesticides in an unsafe manner that poses danger to their health and the environment. ${ }^{16}$ This involves use of banned pesticides, spraying more than the recommended quantity, inadequate protection and unsafe disposal of pesticide wastes. ${ }^{17}$ This was attributed to socioeconomic factors such as experience, age, education status, income or farm size. ${ }^{18,19}$ However, pesticide safety problem among cocoa farmers in developing countries especially in Nigeria cannot be solely attributed to these factors. It was noted that farmers' interactions with stakeholders in supply chain are key to influencing pesticide safety. ${ }^{20}$ Therefore, lack of interactions between cocoa farmers and relevant stakeholders could hamper application of environmentally safe pest management techniques. For example, pesticide retailers could influence farmers pesticide safety decisions depending on the retailers exposure to information. ${ }^{21}$ Thus, understanding an individual risky behaviour (unsafe pesticide use) without exploring other external influence such as responsible stakeholders would be inadequate. Hence, researchers suggested the use of theory-based studies as they provide a good theoretical framework for future intervention designs. Based on this premise, socio-ecological model (SEM) was applied to frame external factors influencing pesticide safety among cocoa farmers. A socio-ecological model proposed by McLeroy ${ }^{22}$ was chosen because it is a framework that describes spheres of multiple environmental or surrounding influences over an individual behaviour. At the center of this framework is an individual whose behaviour is the main interest. This is followed by a figure of growing circles which shows increasing spheres of influence that have impacts on individual behaviour. Based on previous review of this model, various factors that influence individual behaviours are personal, interpersonal, organizational, community and public policies. Regarding this study, the SEM states that cocoa farmer behaviour is under the influence of the farmer individual characteristics and perceptions, pesticide retailers, extension officers, pesticide importers and government agencies (Figure 1). However, only a limited number of studies ${ }^{23-25}$ have used the model to frame agricultural safety among farmers but not within the context of pesticide use. In this regard, little is known about the influence of stakeholders on safe pesticide use especially within the context of cocoa farmers. To the best our knowledge, this is the first study to explore the roles of pesticide stakeholders (especially from stakeholders' perspectives) within the lens of SEM. Therefore, the aim of this study was to explore the influence of pesticide retailers, extension officers, pesticide importers and government agencies on cocoa farmers safe pesticide use in Nigeria.

\section{Theoretical Framework}

The SEM can be defined as a framework of explaining sphere of influence affecting human behaviours. ${ }^{24}$ This dictates that health-seeking behaviour is a product of interaction between an individual attributes and the environmental factors. According to McLeroy SEM model, ${ }^{22}$ there are five sphere of influence affecting human behaviour; these are intrapersonal, interpersonal, community, organization and public policies. Intrapersonal factors involve individual characteristics such as sociodemographic variables, attitudes, beliefs and perceptions. Interpersonal factors are those with close relationship with an individual such as professional, social network, friendship or family networks. 


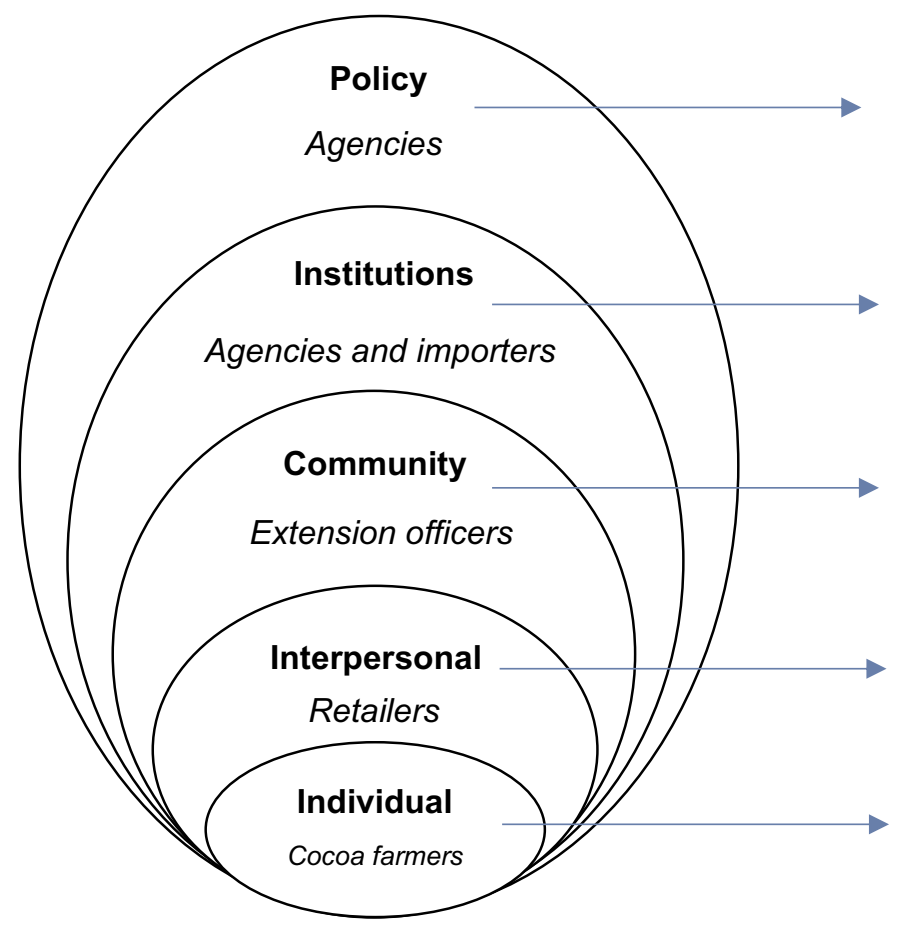

Regulations or policies with respect to pesticide safety on farms

Organizing programs, awareness, workshops, seminars, or trainings to improve pesticide safety behaviour

Selection of pesticides; training of cocoa farmers in safe use and disposal

Advising cocoa farmers on safe use and disposal when purchasing

Sources of information influencing pesticide safety decisions among cocoa farmers

Figure I Socio-ecological model of stakeholders influence on cocoa farmers pesticides use safety of the current study based on Lee. ${ }^{24}$

This could mean pesticide retailers within this study context. Also, there are different concepts of community in the SEM; in this context, it refers to "mediating structures" which connect an individual to a larger society. For example, local extension officers are mediators (or change agents) between the government and rural farmers to facilitate and communicate sustainable and eco-friendly agricultural practices in Nigeria. ${ }^{26}$ The next level is the institution which consists of social organizations or agencies with formal or informal operational regulations. For instance, pesticide safety training programs from various agencies and importers. The last level of influence are public policies concerning pesticide use and safety. In this regard, all the variations of SEM have the following tenets: multiple influences on individual behaviours, interaction of the influences and multifaceted methods for future intervention for behaviour change. Thus, the scope of this study was to focus on direct environmental influences on an individual behaviour at different levels. Therefore, for the purpose and scope of this study and based on the concept of the SEM explained above, the most important stakeholder at different layers of influence were involved in data collections. This was based on previous literature about some of these stakeholders especially the retailers and extension officers in Nigeria. ${ }^{26,27}$ Thus, other stakeholders such as others cocoa farmers, lead cocoa farmers, non-governmental agencies and relevant service providers were not included in the study.

\section{Methods}

\section{Settings and Study Design}

Nigeria is made up of 36 states; fourteen of them are cocoa producers. These cocoa states are classified based on their production capacity (high, medium and low). Cocoa farmers, retailers and extension officers were located in Ondo (high), Ogun (medium) and Kwara (low) while pesticides importers and government agencies were located in Oyo, Lagos and Abuja. This was a qualitative study which aimed to explore the influence of pesticide stakeholders on cocoa farmers pesticide safety using a semi-structure in-depth interview. We used in-depth interview as it provides comprehensive and thorough information about interviewees' perspectives. ${ }^{28}$

\section{Research Instruments}

Semi-structured in-depth interviews guides including demographic questionnaires as well as field notes were used for data collection. The sociodemographic questionnaire was used to retrieve the participants characteristics such as age, marital status, gender, education background and other relevant information. Moreover, Phillippi and Lauderdale $^{29}$ recommended the use of qualitative field notes to triangulate and support the findings from the 
audio transcripts, thus, helped to increase the rigor (validity) of the study. In this regard, we used these notes to pay attention to the participants environment, non-verbal behaviours, displayed sale certificates, training records and available relevant policy documents during the interviews. Cocoa farmers interview guide was developed based on cues to action constructs of the Health Belief Model (HBM) such as information sources regarding pesticide use or safety from the literature. The HBM notes that external cue is needed to trigger decision-making process in order to accept a recommended safety measures. ${ }^{30}$ Also, interview guides for the stakeholders were developed based on other studies from the literature relating to pesticide stakeholders. Then, all the participants were asked same questions (Supplementary Table S1) followed by probing questions (prompts) such as "Can you explain more? Can you give examples? Why?". This was necessary to ensure clarification of details during the interviews. Also, in-depth interview guides were piloted among eight participants representing all the stakeholders in a different location (Osun state). This was done to improve the interview questions before the actual interviews thereby ensuring the questions validity based on the recommendations of Dikko. ${ }^{31}$

\section{Data Collection}

The purposeful selection of total number of informationrich participants $(n=57)$ concerning pesticide safety was based on some inclusion criteria. ${ }^{32}$ The inclusion criteria for cocoa farmers $(n=23)$ were both males and females who resided in farming communities in Ondo, Ogun and Kwara states, communicated in a local language (Yoruba), planted mainly cocoa and used fungicides, herbicides and insecticides. For retailers $(n=15)$, the criteria were both males and females who sold fungicides, herbicides and insecticides, resided in the farmers communities and did not have other occupations. For extension officers $(n=6)$, the criteria were both males and females who worked in the department of agriculture, were responsible for cocoa farmers training and worked for the state government of Ondo, Ogun and Kwara. The criteria for pesticide importers $(\mathrm{n}=7)$ were both males and females who worked for pesticide importers that dealt with cocoa farmers. For personnel of government agencies $(n=6)$, the inclusion criteria were both males and females who were the head of a department or regional directors in their respective agencies and were responsible for cocoa farmers training on pesticide safety.
Prior to starting the interviews, potential participants were approached to engage them on the study purpose in order to build positive rapport with them and have their trust and cooperation. After, the participants were identified based on study selection criteria. Then, final number of participants for this study was determined by applying the principle of data saturation. ${ }^{33}$ This involved continuous and simultaneous data collection and analysis until no new insights emerged from the participants; for this reason, interviews were stopped. ${ }^{34}$ At the end, 57 cocoa and related participants, in total, were interviewed across different locations. First, in-depth interviews were conducted with twenty-three cocoa farmers in Ondo, Ogun and Kwara states to explore their primary information sources that influenced their pesticide safety decisions. We interviewed all the farmers in their farmhouses. Second, interviews were conducted with fifteen pesticide retailers across Ondo, Ogun and Kwara states to explore the safety advice they passed to cocoa farmers when buying from their stores. During the interview, retailers were asked to demonstrate how they pass information to the farmers; all the interviews occurred in their selling points (open markets). Third, six local extension officers were interviewed across the three states previously mentioned to know their involvement in giving extension courses to cocoa farmers. The interviews were conducted at their respective government offices. Fourth, interviews were also carried out with seven personnel from pesticide importing companies selected from Oyo and Lagos states concerning pesticide trainings or workshops. Finally, indepth interviews were also conducted with six personnels from four government agencies dealing with pesticides. They were four departmental heads and two regional directors. The departmental heads were questioned about their agencies roles as regards pesticide safety programs, trainings or workshops for cocoa farmers. While the directors were queried about environmental policies regarding pesticide safety among the farmers. Each interview took about 55 to 90 mins and was conducted by the first author who was supported by two research assistants that helped with audio recordings and note takings.

\section{Ethical Considerations}

The study was conducted according to the declaration of Helsinki as the participants right to confidentiality and anonymity were protected by not identifying them with their real names. Moreover, more than half of the 
participants in the study especially the cocoa farmers and pesticide retailers had low education status. In addition, most of the participants were uncomfortable with document signing due to their perceptions about official forms and organizational factors (such as rules regarding interviews). Therefore, verbal informed consents were sought and obtained before the commencement of data collection. The information sheet and consent form were read to all the participants before the interview concerning the study objectives, procedures, and risks and benefits; then, the participants were allowed to ask questions. After the explanation, the study participants were each given a copy of information sheet and consent form for review either personally or indirectly through an education family members (especially for cocoa farmers and pesticide retailers) and were given enough time to decide whether to take part or not. The whole consent process was recorded by using audio-tape and later transcribed. Thus, the study including information sheets and consent forms was approved by the Ethics Review Committee of Chulalongkorn University, Thailand (COA No. 028/ 2020). In addition, the study participants were given a token appreciation (gift cards) for their time after the interview. Moreover, all the participants were allowed to withdraw from the study at any time without any notice.

\section{Data Analyses}

We transcribed the audio recordings in a local language (Yoruba) and translated into English language before analysis. We expected the influences on cocoa farmers safe pesticide use to occur at individual, interpersonal, community, institutional and policy levels, based on the theoretical framework of this study. We analyzed the data manually from all the respondents using content analysis technique. ${ }^{35}$ This involved sorting the transcripts into meaning units (answers that are related to study objectives). Then, each meaning unit was labeled with codes according to different levels of influence (Table 1). All aspects of the transcripts were identified to confirm if they were included in the list of meaning units by re-reading the original transcripts and comparing with final list of meaning units. Therefore, homogenous groups of meaning units were identified based on interview questions and exact words of the respondents were used in the final analysis. The criteria of Lincoln and Guba was used to ensure rigor of a qualitative study; this involved credibility, transferability, confirmability and dependability. ${ }^{36}$ Credibility was ascertained by using prolonged engagement with the settings, pilot study (to refine the interview guide) and field notes. In addition, two experienced researchers independently transcribed and coded the transcripts for consistency. Transferability was obtained by selecting information-rich participants across different locations using inclusion criteria in order to have different perspectives. For example, we made sure that the selected cocoa farmers came from major three cocoa producing regions and the stakeholder also came from different location that was consistent with their roles in pesticide distribution in Nigeria. Also, we used data saturation (a situation when no new insights emerged from the interviews) to arrive at the final number of respondents for the study. Confirmability was ensured through the process of member checking where transcripts were reviewed by all the participants for accuracy and using actual recordings of interviewee statement. Moreover, different data sources from stakeholders in various locations were used to gain holistic understanding of cocoa farmers safety in pesticide use and disposal. Lastly, dependability was achieved by using thick description of research findings, the settings, selection criteria, data collection and analysis.

\section{Results}

\section{Description of the Study Participants}

Fifty-seven in-depth interviews were conducted among cocoa farmers and different stakeholders across different locations in Nigeria. The participants were within the age range of 20 to 70 years. Thirty-nine of them were males while the remaining eighteen were females. Also, forty of our interviewees were married and only seventeen respondents had no form of education. The in-depth interviews were analyzed and coded using socio-ecological framework which categorized the study findings into personal, interpersonal, community, institutional and policy influence on cocoa farmers safe pesticide use (Table 1).

\section{Theme I: Personal Influence (Cocoa Farmers)}

Cocoa farmers were asked about their primary source of information regarding pesticide use decision from Table 2; seventeen cocoa farmers stated that they relied on pesticide retailers in their respective communities because of their close proximity:

Anytime I have issues with pests or diseases on my farm, I call my chemical sellers who recommend what to do as they are easy to access because of their closeness to my community. Though, we don't always discuss safety measures because they think I am experienced with pesticides handling. (CF 3) 
Table I Codes Extracted from the Interviews

\begin{tabular}{|c|c|c|}
\hline Themes & Codes & n (\%) \\
\hline \multirow[t]{2}{*}{ Policy influence (Government agencies: Regional directors; $n=2$ ) } & -Ineffective policy implementation & $2(100)$ \\
\hline & $\begin{array}{l}\text {-Lack of policies on pesticide registration, use } \\
\text { and disposal }\end{array}$ & $2(100)$ \\
\hline \multirow{4}{*}{$\begin{array}{l}\text { Institutions influence (Pesticide importers; } n=7 \text { ) (Government agencies: } \\
\text { Department heads; } n=4 \text { ) }\end{array}$} & -Inconsistent trainings & $7(100)$ \\
\hline & $\begin{array}{l}\text {-Pesticide labelling challenges due to market } \\
\text { dynamics }\end{array}$ & $7(100)$ \\
\hline & -Lack of disposal mechanisms & $7(100)$ \\
\hline & -Inadequate financial resources & $4(100)$ \\
\hline \multirow[t]{4}{*}{ Community influence (Extension officers; $n=6$ ) } & -Insufficient extension courses & $6(100)$ \\
\hline & -Poor rural road networks & $6(100)$ \\
\hline & -Lack of motivation & $3(50)$ \\
\hline & -Inadequate human resources & $3(50)$ \\
\hline \multirow[t]{4}{*}{ Interpersonal influence (Pesticide retailers; $n=15$ ) } & $\begin{array}{l}\text {-Not accepting responsibility regarding } \\
\text { pesticides advice }\end{array}$ & II (73.3) \\
\hline & -Being a member of agrochemical associations & $3(20.0)$ \\
\hline & -Wrong assumptions about farmers expertise & $9(60.0)$ \\
\hline & $\begin{array}{l}\text {-Inadequate knowledge of product } \\
\text { characteristics }\end{array}$ & $12(80.0)$ \\
\hline \multirow[t]{3}{*}{ Personal influence (Cocoa farmers; $n=23$ ) } & -Lack of safety information from retailers & $17(73.9)$ \\
\hline & -Lack of trust in retailers advice & $10(43.5)$ \\
\hline & -Inadequate trainings from other stakeholders & $18(78.3)$ \\
\hline
\end{tabular}

However, ten of the farmers do not have trust in their retailers information except that they buy pesticide from them:

Retailers rarely provide information concerning pesticide types and guidelines but not safety after purchase, at times when they do, I don't trust any information from most of

Table 2 Cocoa Farmers Main Source of Information Regarding Pesticide Use

\begin{tabular}{|l|c|}
\hline Information Source & $\mathbf{n}$ \\
\hline Extension officers & 3 \\
\hline Pesticide retailers & 17 \\
\hline Pesticide importers & 2 \\
\hline Government agencies & $\mathrm{I}$ \\
\hline
\end{tabular}

the retailers, because majority of them pretend to possess technical skills about these chemicals. They only want to make profits. (CF 11)

Most importantly, training from extension officers, pesticide importers and government agencies were perceived to be inadequate. Eighteen of the farmers reported lack of attention from relevant stakeholders:

Government agencies, pesticide importers or extension officers do organize trainings or workshops, but not for small scale cocoa farmer like me. It is only large-scale farmers that benefit from such opportunity. (CF 21)

\section{Theme 2: Interpersonal Influence (Pesticide Retailers)}

In this study, information dissemination from pesticide retailers (primary information source for cocoa farmers) 
were not encouraging. First, eleven of them thought that it was not their duty to advise cocoa farmers on pesticide safety and disposal: "I believe the farmers are experts in their job. There is no reason for me to tell them about how to safely use pesticides" (PR 25). Second, nine retailers only advised farmers on the type and price of different pesticides: "I only advise them about different types of these chemicals and give them the price. The farmers know what to do with the chemicals" (PR 30). Also, twelve retailers in this study have little understanding about the characteristics of pesticide products they sell. For example, the retailers could not read the information on pesticide labels when asked as their advice was based on experience from long years of selling the products:

I have been in this business for long years and have a lot of experience regarding these products. So, I advise the farmers based on my experience not the labels. (PR 27)

Also, membership of an association was found to influence very few retailers with respect to information they provided cocoa farmers. Three retailers from this study belonged to credible agrochemical associations within their locations where they got regular trainings about pesticide risks and safety precautions:

I make sure all the farmers that purchase my chemicals are properly informed and reminded about how to use and protect themselves because this was what I was trained to do from my association. If I refuse to advise them, my membership registration may be revoked which might adversely affect the benefits I got from them. (PR 35)

\section{Theme 3: Community Influence (Extension Officers)}

Contributions from extension officers regarding pesticide safety courses or trainings were also insufficient as they did not have regular contacts with cocoa farmers:

We don't regularly have extension courses or training with them (cocoa farmers). It is once in a while. For example, we have not had any training visits cocoa farmers this year. (EO 40)

One of the reasons cited was due to lack of motivations from the government despite showing interest in their work. Two of them said that "The monthly take-home and allowances are not encouraging and proportional to the kind of work being carried out on the field" (EO 42).
Another extension officer complained about lack of incentives (such as basic amenities) to motivate them at work:

Going to rural areas to train farmers is important but imaging a situation where you have to stay in a location without basic amenities such as clean water and electricity would be very challenging. So, one needs to be motivated in order to carry out all these duties regarding pesticide use training. (EO 41)

Furthermore, inaccessibility to information regarding current safety courses was identified during the interview as one of the hindrances according to all the personnel. For example, they reported unavailability of modern training materials:

For the past few years, I have been using the same type of training material which is not good enough to convey practical or evidence-based messages to these farmers. (EO 43)

Besides, all the extension officers also talked about inadequate transportation facilities to access rugged rural roads leading to the farmers communities:

It is difficult to access these farmers due to poor road network leading to their communities, at times one has to travel for longer hours using commercial motorcycles to reach the farmers. (EO 44)

Moreover, dearth of human resources was another problems hindering extension trainings based on response from three officers:

There are shortages of extension officers to cover all the agricultural communities. In most cases, an extension officer is assigned to various cocoa farmers in different communities which result in heavy workload. (EO 39)

\section{Theme 4: Institutional Influence (Pesticide Importers and Government Agencies)}

All the seven interviewed personnel of pesticide importers admitted that they only organized training programs or workshops during farming seasons which is just two times a year. In some cases, the training was every other year depending on logistics. Also, all of them said their companies do organize trainings, but they only concentrate on farm leaders or influencers who were expected to train other cocoa farmers in their communities:

Our organization normally train lead farmers for instance the cocoa farmers' association leaders on responsible use of pesticides, general hazard of pesticides and other safety precautions and normally do it inform of workshops. We 
train lead farmers because they always adopt new technology; they would want to use new pesticide products and once they do other cocoa farmers would follow. In addition, we also educate them on application rate, the use of protective equipment before, during and after spraying and the pictograms on pesticide labels. (PI 47)

Regarding pesticide labels, illiterate cocoa farmers were advised to consult relatives who can assist them according to five of the personnel: "We always tell the farmers who cannot speak English to consult any family members who is fluent in the language" (PI 45). According to them, it would be difficult to label pesticide products in local languages because of the forces of demand and supply regarding the products distribution across the country. For example, they said

due to market dynamics, we do withdraw products in a region of the country where they have excess supply and transfer to another region with scarcity. In addition, the chemicals are not produced here (Nigeria), we imported them from abroad, hence, it will not be easy to change the label language. As a result, we use English language that everyone in different regions can relate with. (PI 49)

Though the farmers were trained on how to clean the containers after use but there was no disposal mechanism in place for them according all the personnel queried:

We don't have disposal mechanisms, but we train them on disposal methodology such as how to cleanse or triplerinse empty containers and dispose. We don't have withdrawal mechanisms because there are no storage systems for disposal or recycling. This could only be possible only if pesticides are manufactured in Nigeria. (PI 51)

Moreover, in-depth interview with four departmental heads of four government agencies revealed that they do organize trainings or workshops for cocoa farmers sometimes. Meanwhile, due to lack of adequate budget, all the four agencies interviewed were unable to organize frequent trainings:

We do train the farmers sometimes but not regularly. Normally, trainings should be done regularly with the farmers to refresh their memory if there is enough budgetary allocation. (GA 53)

Also, they all revealed that less emphasis was placed on pesticide safety during trainings as they include other important topics:
Due to lack of financial resources, we try to package all the trainings or workshops in one visit. Therefore, we do not solely put more emphasis safety components due to other crucial aspect of cocoa farming. (GA 52)

\section{Theme 5: Policy Influence (Government Agencies)}

Policies relating to provision of safe storage facilities and ensuring the disposal of hazardous waste in an environmentally sound manner were reported by the two regional directors interviewed from two government agencies (GA 56 and 57). However, these policies were not effectively implemented due to lack of capital and human resources. Analysis from the two in-depth interviews revealed that there were currently no policies in place that encourage research on less toxic or non-chemical control measures for farmers or cover their registration in Nigeria. Moreover, it was reported that there were no policies that prescribed the use of personal protective equipment (PPE) for pesticide application and promote subsidy schemes on less toxic but expensive pesticides. We also noted that there was no regulation in place for the disposal of empty containers. Furthermore, policies on farmers responsibilities and accumulation of pesticide containers were not covered in national environmental regulations. More importantly, policy for the implementation of pesticide waste collection scheme through relevant industries was also lacking. Furthermore, regulations on labeling and pesticide regulatory approval were also currently lacking in Nigeria. For labeling, there were no regulations especially on guidelines for use, legal requirement about pesticide use according to the label instructions and label warning against empty container reuse, instructions for storage and waste disposal. Pesticide registration policy only outlined pesticides registration system in accordance with national requirement, registration process and registration body.

\section{Discussion}

In this study, the influence of stakeholders on safe pesticide use among cocoa farmers in Nigeria was explored. Consequently, five levels of influence were discussed; they were personal (cocoa farmers), interpersonal (pesticide retailers), community (local extension officers), institutions (pesticide importers and government agencies) and policy actors (government agencies). 
Understanding the farmers information or advice sources relating to pesticide safety is vital. This study focused on external cues such as information from pesticide retailers, extension officers, pesticide importers and government agencies. In this study, majority of the cocoa farmers relied on retailers for pesticide information while very few got information from other stakeholders. Specifically, information from retailers to cocoa farmers involved recommendations about types of pesticides. ${ }^{26}$ However, these recommendations did not involve safety precautions because of the retailers belief about cocoa farmers ability in pesticide handling. Furthermore, pesticide safety decision-making does not depend only on information sources but also on farmers' trusts in the information providers. ${ }^{1}$ Hence, cocoa farmers in this study do not have trust especially in retailers information. This agreed with a study among farmers in China. ${ }^{37}$ Moreover, majority complained about lack of trainings from extension officers, pesticide importers and government agencies who only organized trainings for large-scale cocoa farmers unlike the small-scale farmers in this study.

Furthermore, the primary information source for cocoa farmers in this study were pesticide retailers. Findings from this study showed that most retailers did not take responsibility of sharing pesticide safety information with cocoa farmers. This was consistent with a study in Cameroon on pesticide use in cocoa sector. ${ }^{38}$ Nevertheless, the retailers only shared information about types and price of different brands of pesticides being sold. As a result, lack of quality advice from retailers could result in unsafe pesticide use among cocoa farmers. ${ }^{39}$ In addition, retailers from this study who belonged to agroinput associations regularly advised cocoa farmers about pesticide risks whenever they sold. This agrees with a similar study in China where retailers who belonged to an association advised farmers on safe pesticide use. ${ }^{37}$ Moreover, the majority of retailers in this study have little understanding about the characteristics of the products they sold as they could not read pesticide labels; they advised cocoa farmers based on pesticide sales experience. This result is similar to a study in Ethiopia where pesticide retailers advised farmers based on their long years of pesticide sale experience. ${ }^{20}$ Therefore, effective and accurate verbal communication between retailers and farmers is important as it serves as a platform where farmers learn about pesticide risks. ${ }^{37}$ Moreover, extension education in our study was generally weak and inadequate due to lack of motivations such as incentives which was congruent with prior studies. ${ }^{3,40,41}$ According to a previous study, ${ }^{42}$ "motivation of person towards a certain procedure determine the quality of activity that is performed" and subsequently orient or inform a particular behaviour. Also, lack of human resources were another constraint against effective extension education in this study. Access to resources motivates actors or stakeholders and motivation will in turn be influenced by access to information at the disposal of actors. ${ }^{43}$ For instance, resources are very crucial for information gathering and vice versa, thus, leading to effective training which contributes to environmental safety in pesticide use and disposal. ${ }^{20}$

Furthermore, pesticide importers in the current study do organize regular training programs for cocoa farmers. They trained them on general hazards, application rates, use of protective equipment and interpretation of pictograms on labels. However, these trainings did not include small-scale cocoa farmers; this was consistent with a prior study. ${ }^{20}$ They only involved the lead farmers who they believe would influence other farmers to adopt a new technology that reduce pesticide exposure on farms. Besides, all the importers do not use local languages which are well understood by cocoa farmers to write label information due to what was termed "market dynamics". Due to multilinguistic nature of Nigeria, it would be difficult to move pesticide products across regions with different language of instructions, hence the use of English which is the country official language. The rationale behind this was that cocoa farmers can always give the products to an educated family members who would translate for them. Pesticide disposal is an essential components of responsible use of pesticides. Whereas, all pesticide importers in this study lacked disposal mechanisms to withdraw or recycle pesticide wastes from the farmers due to unavailability of facilities for hazardous waste disposal. Our finding was similar to a pilot study in Mauritius. ${ }^{44}$ Moreover, the interviewed departmental heads in this study stated that cocoa farmers trainings or workshops were inadequate due to budget constraint which is also in line with another study among stakeholders in Ghana ${ }^{41}$ In addition, it was reported that safety measures during pesticide use was not emphasized during visits. Hence, lack of emphasis on safety measures in any training programs could undermine farmers pesticide safety decisions. ${ }^{45}$ Lastly, it was revealed that there were policies concerns regarding safe pesticide use and disposal in Nigeria. This was consistent with the findings of a previous study. ${ }^{46}$ These concerns involve pesticide 
registration, end user protection, disposal mechanism and weak implementation of existing regulations. For instance, absence of these regulations could directly or indirectly affect the quality of labels (such as pictograms or safety information) and invariably influence cocoa farmers understanding of the safety information on them. Likewise, lack of regulation on the registration of less toxic or non-chemical alternatives could contribute to the proliferation highly hazardous or hazardous pesticides in the market for cocoa farmers to use.

\section{Conclusion and Recommendations}

Generally, information dissemination between cocoa farmers and related stakeholders was inadequate, thus, undermining safe pesticide use. Cocoa farmers complained about lack of information from the relevant stakeholders (extension officers, pesticide importers and government agencies) regarding pesticide use except pesticide retailers. However, safety information from the retailers were found to be lacking due to their monetary interests rather than human health and the environment. In addition, most retailers had no understanding about the characteristics of products they sold as they could not read pesticide labels. Motivation as well as human resources were hindering effective extension education in the rural communities. Pesticide importers took efforts to train the farmers within their network, but majority of this training focused on lead farmers who were expected to disseminate the information to others. Besides, the agencies do organize training or workshop, but it was insufficient due to budget constraint. Environmental or agri-policies relating to farmers safety in pesticide use and disposal were inadequate in Nigeria. Meanwhile, the outcome of this study could be used to inform pesticide policy recommendations that could improve safety in pesticide use. First, at individual level, forums or meetings where safety needs concerning pesticide use are discussed should be organized with other stakeholders by cocoa farmers through their leaders. Second, provision of regular trainings for retailers is very crucial to improve their pesticide risk knowledge, thereby enabling them to provide reliable information that could be trusted by the farmers. Also, pesticide retailers who are not members of any credible agrochemical associations should be encouraged to participate in their meetings. Their knowledge could be enhanced if the government authorities in Nigeria could set up a training program using those retailers who are members of agrochemical associations as peer educators to encourage other retailers. The capacity and coverage of extension system in Nigeria should be revamped and strengthened by recruiting more personnels, giving incentives to encourage them and providing facilities and financial resources to execute trainings. For pesticide importers, they should be involved in implementation of improved environmental governance regarding safe pesticide use. From ethical perspectives, it is preferable to include those who are explicitly responsible for a problem in the governing process. Also, pesticide importers need to build active collaborations with government agencies to promote safer or biological alternatives as well as the use of integrated pesticide management (IPM). Government agencies also need to develop mechanisms to monitor information exchange among other stakeholders with respect to safe pesticide use among cocoa farmers in Nigeria. However, this call for strong political will from policy influencers and active stakeholders' participation.

\section{Acknowledgments}

Our appreciation goes to the Graduate School, Chulalongkorn University as the research grant funds have been provided by The 100th Anniversary Chulalongkorn University Fund for Doctoral Scholarship. We are also grateful to the Center of Excellence on Hazardous Substance Management (HSM), Chulalongkorn University for providing research fund for this study. Also, this research was supported by the 90th Anniversary of Chulalongkorn University, Ratchadaphiseksomphot Fund and partially supported from the Grant for International Research Integration: Chula Research Scholar (Ratchadaphiseksomphot Endowment Fund), GCURS 59-06-79-01. Finally, we appreciate the support from NIEHS CEED Grant (P30ES005022) and The New Jersey Agricultural Experiment Station at Rutgers University.

\section{Disclosure}

The authors reported no conflicts of interest for this work.

\section{References}

1. Ali MP, Kabir MMM, Haque SS, et al. Farmer's behavior in pesticide use: insights study from smallholder and intensive agricultural farms in Bangladesh. Sci Total Environ. 2020;747:141160. doi:10.1016/j. scitotenv.2020.141160

2. ILO (International Labour Organization). Code of practice on safety and health in agriculture. Meeting of experts to adopt a code on safety and health in agriculture, Geneva, Switzerland; 2010. Available from: http://www.ilo.org/wcmsp5/groups/public/-dgreports/-dcomm/publ/ documents/publication/wcms159457.pdf. Accessed May 21, 2021. 
3. Fan L, Niu H, Yang X, et al. Factors affecting farmers' behaviour in pesticide use: insights from a field study in northern China. Sci Total Environ. 2015;537:360-368. doi:10.1016/j.scitotenv.2015.07.150

4. Miller G. Sustaining the Earth, Thompson Learning, Inc. Pacific Grove, California. Vol. 9. 2004:211-216.

5. Zhang X, Zhao W, Jing R, et al. Work-related pesticide poisoning among farmers in two villages of Southern China: a cross-sectional survey. BMC Public Health. 2011;11(1):1-9. doi:10.1186/1471-2458-11-429

6. Walton AL, LePrevost C, Wong B, Linnan L, Sanchez-Birkhead A, Mooney K. Observed and self-reported pesticide protective behaviors of Latino migrant and seasonal farmworkers. Environ Res. 2016;147:275-283. doi:10.1016/j.envres.2016.02.020

7. Remoundou K, Brennan M, Sacchettini G, et al. Perceptions of pesticides exposure risks by operators, workers, residents and bystanders in Greece, Italy and the UK. Sci Total Environ. 2015;505:1082-1092. doi:10.1016/j.scitotenv.2014.10.099

8. Mariyono J, Kuntariningsih A, Suswati E, Kompas T. Quantity and monetary value of agrochemical pollution from intensive farming in Indonesia. Manag Environ Qual. 2018;29(4):759-779. doi:10.1108/ MEQ-03-2017-0030

9. Siriwong W, Ong-artborirak P, Nganchamung T, Siriwat S, Robson M. Factors associated with health effects from occupational exposure to pesticide residues among greengrocers in fresh market, Bangkok, Thailand. Hum Ecol Risk Assess. 2019;25(3):590-601. doi:10.1080/10807039.2018.1464900

10. Berni I, Menouni A, El IG, et al. Understanding farmers' safety behavior regarding pesticide use in Morocco. Sustain Prod Consum. 2021;25:471-483. doi:10.1016/j.spc.2020.11.019

11. Bagheri A, Emami N, Damalas CA. Farmers' behavior towards safe pesticide handling: an analysis with the theory of planned behavior. Sci Total Environ. 2021;751:141709. doi:10.1016/j. scitotenv.2020.141709

12. Food and Agricultural Organization (FAO). Pesticides use; 2020. Available from: http://www.fao.org/faostat/en/\#data/RP. Accessed May 4, 2021.

13. Bakker L, Sok J, Van Der Werf W, Bianchi F. Kicking the habit: what makes and breaks farmers' intentions to reduce pesticide use? Ecol Econ. 2021;180:106868. doi:10.1016/j.ecolecon.2020.106868

14. Luther GC, Mariyono J, Purnagunawan RM, Satriatna B, Siyaranamual M. Impacts of farmer field schools on productivity of vegetable farming in Indonesia. Paper presented at: Natural Resources Forum; 2018.

15. National Bureau of Statistics. Nigerian gross domestic product report (Q2 2020); 2020. Available from: https://www.nigerianstat.gov.ng/ pdfuploads/GDP_Report_Q2_2020.pdf. Accessed September 20, 2020.

16. Osewa S, Alamu O, Okonkwo H, Adetiloye I, Ajayi D. Occupational hazards and safety practices of cocoa farmers in Obokun Local Government of Osun State. Greener J Agric Sci. 2013;3 (12):823-828. doi:10.15580/GJAS.2013.3.060913822

17. Aminu F, Edun T. Environmental effect of pesticide use by cocoa farmers in Nigeria. J Res For Wildl Environ. 2019;11(4):153-163.

18. Aminu F, Ayinde I, Sanusi R, Olaiya A. Determinants of pesticide use in cocoa production in Nigeria. Can J Agric Crops. 2019;4 (2):101-110. doi:10.20448/803.4.2.101.110

19. Sowunmi FA, Famuyiwa GT, Oluyole KA, Aroyeun SO, Obasoro OA. Environmental burden of fungicide application among cocoa farmers in Ondo state, Nigeria. Sci Afr. 2019;6:e00207. doi:10.1016/j.sciaf.2019.e00207

20. Mengistie BT, Mol AP, Oosterveer P. Private environmental governance in the Ethiopian pesticide supply chain: importation, distribution and use. NJAS Wagen J Life Sci. 2016;76:65-73. doi:10.1016/j. njas.2015.11.005

21. Yang X, Wang F, Meng L, et al. Farmer and retailer knowledge and awareness of the risks from pesticide use: a case study in the Wei River catchment, China. Sci Total Environ. 2014;497-498:172-179. doi:10.1016/j.scitotenv.2014.07.118
22. McLeroy KR, Bibeau D, Steckler A, Glanz K. An ecological perspective on health promotion programs. Health Educ Q. 1988;15 (4):351-377. doi:10.1177/109019818801500401

23. Keifer M. Think of it again, apply it anew: the socio-ecological model and farm safety. J Agromedicine. 2017;22(4):293-294. doi:10.1080/1059924X.2017.1358970

24. Lee BC, Bendixsen C, Liebman AK, Gallagher SS. Using the socio-ecological model to frame agricultural safety and health interventions. J Agromedicine. 2017;22(4):298-303. doi:10.1080/ 1059924X.2017.1356780

25. Prado JB, Mulay PR, Kasner EJ, Bojes HK, Calvert GM. Acute pesticide-related illness among farmworkers: barriers to reporting to public health authorities. J Agromedicine. 2017;22(4):395-405. doi:10.1080/1059924X.2017.1353936

26. Mokwunye I, Babalola F, Asogwa U, et al. Compliance of agrochemical marketers with banned cocoa pesticides in southwest Nigeria. J Agric Sci Belgrade. 2014;59(2):161-174. doi:10.2298/ JAS1402161M

27. Mokwunye I, Babalola F, Ndagi I, Idrisu M, Mokwunye F, Asogwa E. Farmers' compliance with the use of approved cocoa pesticides in cocoa producing States of Nigeria. J Agric Soc Res. 2012;12(2):44-60.

28. Turner III DW. Qualitative interview design: a practical guide for novice investigators. Qual Rep. 2010;15(3):754.

29. Phillippi J, Lauderdale J. A guide to field notes for qualitative research: context and conversation. Qual Health Res. 2018;28 (3):381-388. doi:10.1177/1049732317697102

30. Strecher VJ, Rosenstock IM. The health belief model. Cambridge Handbook Psychol Health Med. 1997;113:117.

31. Dikko M. Establishing construct validity and reliability: pilot testing of a qualitative interview for research in Takaful (Islamic insurance). Qual Rep. 2016;21(3).

32. Gentles SJ, Charles C, Ploeg J, McKibbon KA. Sampling in qualitative research: insights from an overview of the methods literature. Qual Rep. 2015;20(11):1772-1789.

33. Mason M. Sample size and saturation in $\mathrm{PhD}$ studies using qualitative interviews. Paper presented at: Forum qualitative Sozialforschung/Forum: qualitative social research; 2010.

34. Saunders B, Sim J, Kingstone T, et al. Saturation in qualitative research: exploring its conceptualization and operationalization. Qual Quant. 2018;52(4):1893-1907. doi:10.1007/s11135-017-0574-8

35. Bengtsson M. How to plan and perform a qualitative study using content analysis. NursingPlus Open. 2016;2:8-14. doi:10.1016/j. npls.2016.01.001

36. Guba EG, Lincoln YS. Epistemological and methodological bases of naturalistic inquiry. ECTJ. 1982;30(4):233-252.

37. Jin S, Bluemling B, Mol AP. Information, trust and pesticide overuse: interactions between retailers and cotton farmers in China. NJAS Wagen J Life Sci. 2015;72:23-32. doi:10.1016/j.njas.2014.10.003

38. Mahob R, Ndoumbe-Nkeng M, Ten Hoopen GM, et al. Pesticides use in cocoa sector in Cameroon: characterization of supply source, nature of actives ingredients, fashion and reasons for their utilization. Int J Biol Chem Sci. 2014;8(5):1976-1989. doi:10.4314/ ijbcs.v8i5.3

39. Oluwole O, Cheke RA. Health and environmental impacts of pesticide use practices: a case study of farmers in Ekiti State, Nigeria. Int J Agric Sustain. 2011;7(3):153-163. doi:10.3763/ijas.2009.0431

40. Jallow MFA, Awadh DG, Albaho MS, Devi VY, Thomas BM. Pesticide risk behaviors and factors influencing pesticide use among farmers in Kuwait. Sci Total Environ. 2017;574:490-498. doi:10.1016/j.scitotenv.2016.09.085

41. Kwakye MO, Mengistie B, Ofosu-Anim J, Nuer ATK, Van den Brink PJ. Pesticide registration, distribution and use practices in Ghana. Environ Dev Sustain. 2019;21(6):2667-2691. doi:10.1007/ s10668-018-0154-7 
42. Mengistie BT, Mol AP, Oosterveer P, Simane B. Information, motivation and resources: the missing elements in agricultural pesticide policy implementation in Ethiopia. Int J Agric Sustain. 2015;13 (3):240-256. doi:10.1080/14735903.2014.959330

43. Bressers HT, Xue Y. The feasibility of environmental negotiated agreements in China. Int $J$ Environ Sustain Dev. 2007;6 (3):221-241. doi:10.1504/IJESD.2007.015303

44. CropLife Mauritius. Empty pesticide container management pilot project; 2018. Available from: https://sgp.undp.org/all-documents /country-documents/961-empty-pesticide-container-managementpilot-project/file.html. Accessed February 5, 2021.
45. Gaber S, Abdel-Latif SH. Effect of education and health locus of control on safe use of pesticides: a cross sectional random study. J Occup Med Toxicol. 2012;7(1):3. doi:10.1186/1745-6673-7-3

46. van den Berg H, Gu B, Grenier B, et al. Pesticide lifecycle management in agriculture and public health: where are the gaps? Sci Total Environ. 2020;742:140598. doi:10.1016/j.scitotenv.2020.140598
Risk Management and Healthcare Policy

\section{Publish your work in this journal}

Risk Management and Healthcare Policy is an international, peerreviewed, open access journal focusing on all aspects of public health, policy, and preventative measures to promote good health and improve morbidity and mortality in the population. The journal welcomes submitted papers covering original research, basic science, clinical \& epidemiological studies, reviews and evaluations,
Dovepress

guidelines, expert opinion and commentary, case reports and extended reports. The manuscript management system is completely online and includes a very quick and fair peer-review system, which is all easy to use. Visit http://www.dovepress.com/testimonials.php to read real quotes from published authors. 